\title{
O GLUCONATO DE CLOREXIDINA OU O ÁLCOOL-IODO-ÁLCOOL NA ANTI-SEPSIA DE CAMPOS OPERATÓRIOS EM CÃES
}

\author{
CHLORHEXIDINE GLUCONATE OR ALCOHOL-IODINE-ALCOHOL \\ IN THE ANTISEPSIS OF SURGICAL AREA IN DOGS
}

\author{
Décio Adair Rebellatto da Silva ${ }^{1}$ Mateus Matiuzzi da Costa ${ }^{2}$ \\ Agueda Castagna de Vargas ${ }^{3}$ Marcelo Meller Alievi ${ }^{4}$ \\ João Eduardo Wallau Schossler ${ }^{5}$ \\ Tatiana Resende da Silva ${ }^{2}$
}

\section{RESUMO}

Foi comparada a efetividade da anti-sepsia de sítios operatórios em vinte e quatro animais, subdivididos em três grupos, utilizando água destilada (grupo controle), álcool-iodoálcool (grupo I) e gluconato de clorexidina (grupo II). As amostras foram coletadas através de swab da pele, depois da tricotomia (TO), após anti-sepsia (T1) e duas horas após o uso do antiséptico (T2), e submetidas à contagem de Unidades Formadoras de Colônia $(U F C) / m \ell$. Nos três grupos, ocorreu crescimento

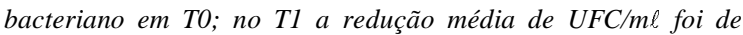
$26,70 \%$ para o grupo controle, $91,61 \%$ para o grupo I e $96,67 \%$ para o grupo II. No T2, as reduções nos respectivos grupos foram de 21,02\%, 91,56\% e 96,89\%. As duas técnicas utilizando antisépticos reduziram significativamente o número de bactérias da pele, tanto no T1 quanto no T2 ( $p<0,05)$. A equiiparidade entre os dois métodos ficou evidenciada, uma vez que não foi encontrada diferença estatisticamente significativa entre eles $(p<0,05)$.

Palavras-chave: anti-séptico, clorexidina, iodo, pele.

\section{SUMMARY}

The efficacy of the antisepsis in a surgical area was compared in twenty four mongrel dogs, divided in three groups, using sterile water, alcohol-iodine-alcohol and chlorhexidine gluconate. All samples of skin swab were collected after thricothomy, after antisepsis, and two hours after application of the antiseptic solution. Samples were collected with a sterile swab and the Colony Formation Unities/m $\ell$ was determined. Bacterial growth were observed in samples from all groups during the first collection. However, at the first counting (T1), the average reduction of CFU/m $\ell$ observed was $26.7 \%$ for the control group, $96.61 \%$ group one, and $96.67 \%$ group two. At the second counting (T2), reductions of $21.02 \%, 91.56 \%$, and $96.89 \%$ for the respective groups were observed. The two antiseptic techniques utilized were able to reduced significantly the number of bacteria present on the skin, at $T 1$ as well as $T 2(p<0.05)$. The equality of these two antiseptic methods was demonstrated since no significant difference $(p<0.05)$ between these treatments was observed.

Key words: antiseptic, chlorhexidine, iodine, skin

\section{INTRODUÇÃO}

A descontaminacão de tecidos vivos vem ganhando importância, principalmente pela conscientização dos profissionais de saúde de que o paciente é a fonte primária de infeccão (RODRIGUES $\boldsymbol{e t}$ al. 1997). Toda a ferida cirúrgica deve ser considerada contaminada (SLATTER, 1993), uma vez que os microrganismos vivem na superfície cutânea, especialmente na camada córnea, e também no interior das glândulas sudoríparas, sebáceas e folículos pilosos (RODRIGUES et al. 1997). O potencial da pele como reservatório de microrganismos com ação contaminante para a ferida cirúrgica é bem conheci-

\footnotetext{
${ }^{1}$ Médico Veterinário, MSc., Professor da Universidade de Cruz Alta, Campus-Parada Benito, 98025-810, Cruz Alta, RS. E-mail: decio@main.unicruz.tche.br. Autor para correspondência.

${ }^{2}$ Aluno de Graduação em Medicina Veterinária, Universidade Federal de Santa Maria (UFSM), bolsista CNPQ.

${ }^{3}$ Médico Veterinário, MSc., Professor Assistente do Departamento de Medicina Veterinária Preventiva, UFSM.

${ }^{4}$ Veterinário, Aluno do Curso de Pós-graduação em Medicina Veterinária, UFSM.

${ }^{5}$ Médico Veterinário, Dr., Professor Adjunto do Departamento de Clínica de Pequenos Animais UFSM.
} 
do (GRÖSCHEL e PRUETT, 1991). Esses microrganismos são reduzidos em número com uma preparação apropriada da pele, minimizando a probabilidade de infecção causada por bactérias presentes na área operatória (STUBBS et al., 1996).

O conhecimento das vias de transmissão de microorganismos causadores de infecção e a identificação dos tipos de bactérias envolvidas com a contaminação cirúrgica permite reduzir a ocorrência e severidade dessas infecções. A microflora endógena do organismo é normalmente a maior fonte de infecção de feridas cirúrgicas, uma vez que os processos de anti-sepsia reduzem efetivamente as bactérias exógenas (SLATTER, 1993). A flora microbiana da pele consiste em dois tipos de microrganismos: transitórios e residentes. A microflora transitória representa contaminantes ambientais recentes, que sobrevivem por curtos períodos na pele (SIMMONS, 1983; GARNER \& FAVERO, 1986; LARSON, 1988) e são consideradas como não colonizantes; entre elas, estão Escherichia coli e outras bactérias gram-negativas. Estes agentes são facilmente removidos pela lavagem simples. Microrganismos residentes, como Staphylococcus coagulase negativa, Corynebacterium sp., Propionibacterium sp., Acinetobacter sp. e certos membros do grupo Klebsiella-Enterobacter não podem ser removidos pela simples lavagem, requerendo o uso de soluções com propriedades antimicrobianas (MURRAY, 1995).

As bactérias mais comumente envolvidas em infecções cirúrgicas são os cocos gram positivos dos gêneros Staphylococcus e Streptococcus. Bacilos gram-negativos de origem fecal podem ser isolados, ocasionalmente, dessas infecções, devido à dificuldade em prevenir a contaminação dos pelos e da pele com estes agentes infecciosos (SLATTER, 1993). As intervenções cirúrgicas começam com a preparação da pele na área de incisão. O objetivo da anti-sepsia é reduzir o número de bactérias com mínimo de prejuízo à pele, reduzindo o risco de infecção no pós operatório (SEBBEN, 1983) .

A clorexidina foi descoberta no final de 1940 e pela sua eficiente ação antimicrobiana passou a ser usada na anti-sepsia da pele (HAUGEN \& JOHANSEN, 1974). Esse anti-séptico pertence ao grupo das biguanidinas e, atualmente, o gluconato de clorexidina (GC), por ser mais solúvel, é a preparação mais utilizada. Sua ação, praticamente, imediata (cerca de 15 segundos após fricção), apresenta baixo potencial de toxicidade, atividade antimicrobiana in vitro contra bactérias gram-positivas, gramnegativas e fungos, bem como baixa irritabilidade, sendo seguro para uso inclusive em crianças recémnascidas (CERQUEIRA, 1997). FOWLER \& SCHUH (1992) demonstram a eficácia do gluconato de clorexidina em estudos in vitro e in vivo em humanos e animais. SANCHEZ et al.(1988) relatou que bactérias, como Staphylococcus aureus, são sensíveis a esse anti-séptico. No entanto, outras bactéiras como Proteus mirabilis, Serratia marcescens, Serratia rubidae e Pseudomonas cepacia podem desenvolver resistência ao gluconato de clorhexidina.

O iodo, composto do grupo dos halogênios, foi utilizado pela primeira vez em 1939, como anti-séptico, na forma de tintura. A principal aplicação desse composto objetiva à anti-sepsia da pele e a sua formulação mais eficiente é na forma de tintura (GOODMAN \& GILMAN, 1987). Seu tempo de ação é quase imediato, devendo, entretanto, ser retirado da pele após secagem, uma vez que ocasiona irritação persistente (DENTON, 1990). O poder bactericida do iodo baseia-se nas alterações do ácido nucléico e da síntese protéica bacteriana. O álcool etílico é um composto químico orgânico, com várias concentrações. A ação germicida é quase imediata, porém não possui ação residual (RODRIGUES $\boldsymbol{e t} \boldsymbol{a l}$. 1997).

Vários agentes e métodos têm sido usados para anti-sepsia da pele, contudo, existe controvérsia de qual apresenta melhor resultado. O presente estudo foi realizado para avaliar e comparar o potencial de redução bacteriana e o efeito residual proporcionado pelo gluconato de clorexicina (GC), e pelo método usando álcool-iodo-álcool (A-I-A); esse utilizado rotineiramente na limpeza da área operatória em pacientes do Hospital Veterinário (HV) da Universidade Federal de Santa Maria (UFSM).

\section{MATERIAL E MÉTODOS}

O experimento foi realizado na sala cirúrgica do Hospital Veterinário e no laboratório de bacteriologia do Departamento de Medicina Veterinária Preventiva, da UFSM. Foram utilizados 24 cães, sem raça definida e sem evidência de doenças cutâneas. Os animais foram separados ao acaso em três grupos: controle, I e II, com oito animais cada um. Após 10 minutos da pré-medicação, via intramuscular, com maleato de acepromazina $(0,2 \mathrm{mg} / \mathrm{kg})$, procedeu-se a tricotomia da região abdominal. Ao final deste procedimento, utilizou-se tiopental sódico, endovenoso $(10 \mathrm{mg} / \mathrm{kg})$, para indução anestésica; os cães foram encaminhados à sala cirúrgica, colocados em decúbito dorsal e preparados para a passagem do swab na pele: logo depois da tricotomia, no tempo zero (T0); logo após a antisepsia, tempo um (T1), e duas horas depois da antisepsia, tempo dois (T2).

Para a delimitação da área de passagem do swab foi utilizado papel alumínio estéril, com 
recorte formando um quadrado de $9 \mathrm{~cm}$, de forma que permitisse quatro passagens do swab previamente embebido em $\mathrm{TSB}^{\mathrm{a}}$ (tryptic soy broth), contendo lecitina ${ }^{\mathrm{b}}$, Tween $80^{\mathrm{c}}$ e Tiossulfato de Sódio ${ }^{\mathrm{d}}$. Após a passagem do primeiro swab na pele, o procedimento anti-séptico realizado em cada grupo foi: - controle: passagem de gaze estéril embebida em água destilada na área cirúrgica para a remoção das sujidades presentes no local, sendo isso repetido por mais duas vezes; - grupo I: remoção da sujidade e de fragmentos celulares com gaze estéril embebida em álcool 92,8 $\mathrm{GL}^{\mathrm{e}}$, com posterior passagem de gaze de tintura de iodo $2 \%$, e seu excesso removido com gaze umedecida em álcool; - grupo II: para a retirada de sujidades, a gaze estéril foi embebida em água destilada estéril, seguida de passagem do gluconato de clorexidine $4 \%^{\mathrm{g}}$ impregnado na gaze. Após seis minutos de contato, o excesso de GC foi retirado com gaze umedecida em água destilada.

O tempo médio de duração da anti-sepsia foi de três minutos, tanto para o grupo controle, quanto para o grupo I. Para o grupo II, foi utilizado um tempo médio de nove minutos, pois o GC ficou agindo por seis minutos, quando, então, retirou-se o excesso do produto, seguindo a descrição de STUBBS et al. (1996).

Após a colheita das amostras na pele, os swabs foram colocados em tubos, contendo $2 \mathrm{~m} \ell$ de TSB. O material foi imediatamente enviado ao laboratório de bacteriologia, onde as amostras eram agitadas vigorosamente por 1 minuto, sendo em seguida diluídas até 1:1000. De cada diluição, foram retiradas alíquotas de $1 \mathrm{~m} \ell$ que foram plaqueadas em meio "tryptic soy ágar"h (TSA), contendo Lecitina, Tween 80 e Tiossulfato de Sódio. As placas foram incubadas a $37^{\circ} \mathrm{C}$ por 48 horas, quando foi realizada a contagem de Unidades Formadoras de Colônia (UFC), / $\mathrm{m} \ell$. Os swabs eram também semeados em ágar sangue ovino $5 \%$, para identificação das bactérias obtidas nos diferentes tempos de colheita. A identificação dos microrganismos isolados seguiu descrição de MURRAY (1995).

O percentual de redução bacteriana após a anti-sepsia (T1) e duas horas depois (T2) foi calculado em cada preparo de pele a partir das contagens de UFC, seguindo o modelo matemático usado por OSUNA et al. (1990b), apresentado a seguir:
Para análise estatística foi realizada uma curva de regressão, para posterior estudo através do teste " $t$ " de Student.

\section{RESULTADOS}

A freqüência de bactérias que cresceram, após a cultura, está distribuída na figura 1. A contagem de bactérias nos diferentes tempos encontra-se relacionada na tabela 1 .

Em relação ao grupo controle, houve crescimento bacteriano em todas as amostras coletadas. A redução média de UFC/m $\ell$, no T1 e T2 foi de $26,7 \%$ e $21,02 \%$, respectivamente. Três amostras apresentaram um número de bactérias maior no T1 em relação ao T0, enquanto duas amostras, um número maior em T2 que no T0. No grupo I, ocorreu crescimento em todas as coletas iniciais. Ao T1, duas amostras foram negativas representando $25 \%$ (2/8), e ao T2, o percentual de UFC negativas, em 48 horas, foi de $37,5 \%$ (3/8). O percentual de redução média foi de $91,61 \%$ ao T1 e $91,56 \%$ ao T2. O grupo II demonstrou $50 \%$ (4/8) das amostras sem crescimento ao T1. O percentual médio de redução nos T1 e T2 foi de $96,67 \%$ e $96,89 \%$, respectivamente.

As duas técnicas utilizando anti-sépticos reduziram significativamente o número de bactérias da pele, tanto no T1 quanto no T2 (p< 0,05). Não houve diferença significativa entre eles $(p<0,05)$.

\section{DISCUSSÃO}

O critério para escolha de um anti-séptico deve basear-se no seu índice terapêutico, o qual é descrito como a relação entre a concentração eficaz contra microrganismos e os efeitos deletérios sobre os tecidos vivos, assim como a interferência nos processo de reparação, cicatrização e irritação local (RODRIGUES, et al. 1997). Segundo PAUL \& GORDON (1978), SEBBEN (1983), OSUNA et al. (1990b), PHILLIPS et al.(1991) o amplo espectro de atividade antimicrobiana, ação rápida, atividade antimicrobiana residual, baixa incidência de irritação da pele, toxicidade baixa e boa atuação na presença de matéria orgânica são qualidades que o antiséptico tópico deve possuir. Evidentemente, é difícil de ser encontrado um anti-séptico que possua todas essas características.

\footnotetext{
Redução imediata de bactérias $(\%)$ = UFC pós -tricotomia - UFC pós - anti -sepsia x 100 (T1) UFC pós tricotomia
}

Redução de bactérias em 2 hs (\%) = UFC pós tricotomia - UFC 2hs pós anti -sepsia x 100 (T2) UFC pós tricotomia 


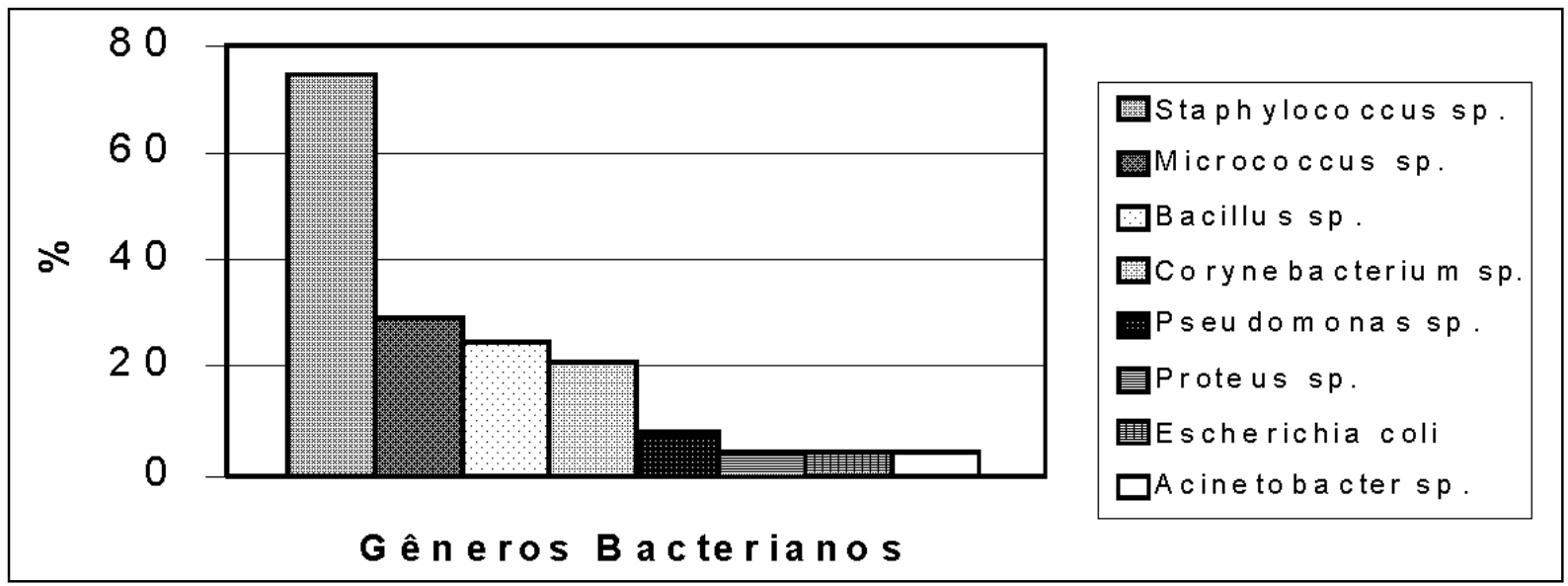

Figura 1 - Prevalência de microorganismos encontrados na pele de cães obtidos por swab imediatamente após tricotomia. Hospital Veterinário, Universidade Federal de Santa Maria 1998.

Segundo STUBBS et al.(1996), o CG é o anti-séptico que melhor preenche essas qualificações. Representa uma alternativa para pacientes alérgicos ao iodo, é pouco absorvido pela pele íntegra e a absorção percutânea, caso ocorra, é insignificante (RODRIGUES et al., 1997). SOUZA et al. (1982), analisando amostras de sangue de pacientes humanos adultos, que fizeram uso da clorexidina durante um período de até 12 meses, não encontraram clorexidina circulante. Contudo, a clorexidina é incompatível com sabão e outros agentes aniônicos (RODRIGUES et al., 1997), podendo apresentar atividade ototóxica e ocasionar lesões oculares (LARSON, 1988).

Os compostos contendo iodo são reconhecidos como potentes germicidas, sendo ativos em relação a uma larga variedade de microrganismos, tais como bactérias, fungos, leveduras, protozoários e, inclusive vírus (GILMORE \& SANDERSON, 1975). Os fatores negativos do iodo, que contribuem para que novas alternativas sejam buscadas são: afinidade por matéria orgânica, que reduz seu potencial oxidante e, conseqüientemente, seu poder germicida (BLATT \& MOLONEY, 1961), absorção do iodo pela vagina e peritôneo (VORHERR $\boldsymbol{e t}$ al. 1980) e, eventualmente, irritação dermal (KAUL \& JEWETT, 1981; BROWN et al.,1984; SANCHEZ et al.,1988; OSUNA et al., 1990b/1990a); OSUNA et al., (1990b) relatam que muitas vezes, associado à dermatite de contato, o prurido com a alteração de pele, desvia a atenção do paciente para a área cirúrgica, resultando em lesões, devido a auto-escoriação no local.

A redução média dos microrganismos, encontrada no grupo controle, foi de $26,70 \%$ em T1 e $21,02 \%$ em T2. Essa redução se deve à remoção mecânica de bactérias transitórias da pele, realizada pela passagem de gaze embebida em água destilada estéril. No entanto, três amostras apresentam uma contagem de UFC maior no T1 do que no T0, e uma maior no T2 que no T0; isso possivelmente ocorreu devido a variações na quantidade de microrganismos em locais diferentes de pele, acúmulo de bactérias pelo movimento de "arrastão" durante a fricção com a gaze ou provável multiplicação e invasão de microbiota residente que, segundo FELLER $\boldsymbol{e t}$ al.(1972), é favorecida pelo uso da tricotomia. A limpeza mecânica sozinha tem mostrado redução na contagem de bactérias na pele, segundo SLATTER (1993), o que explica os resultados obtidos. Yeturraspe, apud GRUMADAS et al. (1991), cita que a flora transitória pode ser removida completamente durante a escovação das mãos com água e sabão, a não ser que ali exista grande contaminação (MURRAY, 1995). SWAIN et al. (1991), estudando a ação dos anti-sépticos em caninos, verificou que, tanto o grupo de soluções anti-sépticas, quanto o grupo controle, constituído de água morna, foram eficazes na diminuição da população microbiana da pele. Assim, na rotina pré-operatória, além da tricotomia deve ser feita cuidadosa lavagem não só na área operatória, mas de toda a superfície corporal do animal.

No presente trabalho, o álcool-iodo-álcool propiciou um percentual de redução bacteriana de 91,61\% logo após anti-sepsia (T1) e 91,56\% duas horas após a aplicação do anti-séptico (T2). Selwin \& Ellis, apud ESCOBAR (1992), encontraram uma redução de $99,6 \%$ da população microbiana da pele, após o uso de soluções contendo iodo. BLATT \& MOLONEY (1961), ao testarem soluções aquosas e alcóolicas de iodo frente a soluções de iodofóros, 
Tabela 1 - Número de bactérias encontradas nos grupos: controle, álcool-iodo-álcool, águagluconato de clorexidina-água em cada cão, antes da anti-sepsia (T0), logo após (T1), e duas horas após anti-sepsia(T2).

\begin{tabular}{|c|c|c|c|c|c|c|c|c|c|c|c|}
\hline \multicolumn{4}{|c|}{ Controle } & \multicolumn{4}{|c|}{ Álcool-iodo-Álcool } & \multicolumn{4}{|c|}{ Água-GC-Água } \\
\hline A & T0 & $\mathrm{T} 1$ & $\mathrm{~T} 2$ & A & T0 & $\mathrm{T} 1$ & $\mathrm{~T} 2$ & A & T0 & $\mathrm{T} 1$ & $\mathrm{~T} 2$ \\
\hline 1 & 470 & 12000 & 153000 & 9 & 102000 & 2000 & 0 & 17 & 200 & 40 & 15 \\
\hline 2 & 8300 & 5300 & 4800 & 10 & 7000 & 2500 & 2300 & 18 & 440 & 0 & 20 \\
\hline 3 & 32200 & 11300 & 100 & 11 & 5600 & 1450 & 25 & 19 & 1860 & 0 & 10 \\
\hline 4 & 7500 & 1200 & 140 & 12 & 5700 & 0 & 290 & 20 & 3050 & 10 & 270 \\
\hline 5 & 1740 & 9250 & 100 & 13 & 5350 & 0 & 70 & 21 & 30000 & 450 & 10 \\
\hline 6 & 130 & 2950 & 50 & 14 & 5100 & 10 & 0 & 22 & 3000 & 0 & 45 \\
\hline 7 & 11900 & 5900 & 11800 & 15 & 15700 & 35 & 0 & 23 & 2150 & 0 & 40 \\
\hline 8 & 171000 & 122000 & 6750 & 16 & 174000 & 5500 & 1530 & 24 & 31200 & 1500 & 10 \\
\hline
\end{tabular}

Dados em UFC /ml, A= Amostra, T0= Tempo zero, T1= Tempo um e T2= Tempo dois.

amostras é mais importante que resultados negativos isolados da contagem bacteriana. Segundo SWAIM et al. (1991), 20\% da microflora residente da pele é inacessível a qualquer tipo de desinfecção, pois estão localizadas nas camadas mais profundas (PENILDON, 1985). Os resultados deste estudo documentam, em condições experimentais, que o uso da tintura de iodo $2 \%$ e GC $4 \%$ ocasiona redução bacteriana significativa $(\mathrm{p}<0,05)$, tanto, logo após antisepsia, como nas duas horas seguintes, demonstrando que os mesmos apresentam adequado

encontraram uma eficiência comparável entre elas. No atual experimento, a eficiência do iodo se mantém inalterada após duas horas da aplicação. STUBBS et al. (1996) afirmam que o GC é efetivo contra bactérias gram-positivas e gram-negativas, incluindo Staphylococcus aureus, Escherichia coli, Enterococcus faecalis e Pseudomonas areuginosa. Seu efeito antibacteriano é relacionado com a ação sobre a membrana celular e precipitação de conteúdo intracelular (SANCHEZ et al., 1988). O percentual médio de redução no grupo em que essa solução anti-séptica foi utilizada, foi de $96,67 \%$ no T1 e $96,89 \%$ no T2. Estes dados são semelhantes aos encontrados por OSUNA et al., (1990b) ao comparar o CG e iodo povidona. Nesse grupo também se observa que o poder anti-séptico se manteve após duas horas de aplicação.

Após aplicação do CG, o mesmo foi deixado agir por seis minutos. Segundo PEREIRA et al. (1990), quanto maior o tempo de contato do gluconato de clorexidina, maior será a redução de UFC, resultando em maior atividade residual. Esta afirmativa foi comprovada neste experimento com baixos números de bactérias, logo após a anti-sepsia e duas horas depois. A água destilada estéril foi usada para retirar o excesso de CG, supondo-se que o álcool etílico poderia diminuir o poder residual do mesmo, no entanto, pesquisadores demonstraram que não existe diferença no efeito residual da clorexidina na pele, quando o excesso retirado com álcool ou salina estéril. (SWAIM \& LEE, 1987; OSUNA et al., 1990b).

No presente trabalho, foram encontradas cinco amostras sem crescimento bacteriano no grupo I, enquanto no grupo II, em quatro amostras não houve crescimento bacteriano em 48 horas. Isso não significa uma redução total na microflora residente da pele, pois a baixa contagem de UFC em várias efeito residual até duas horas da sua aplicação, sem diferença significativa entre os dois grupos no T1 e T2. Este achado é similar ao encontrado por OSUNA et al. (1990b), que compararam o GC com iodo povidona na anti-sepsia de áreas cirúrgicas em cães. KAUL \& JEWETT (1981); PETERSON $\boldsymbol{e}$ t al. (1978); VORHERR et al. (1980), em trabalhos experimentais realizados para verificar a redução da flora microbiana pela anti-sepsia das mãos e campos cirúrgicos em humanos, relatam superioridade do GC em relação ao iodo povidona.

Na tabela 1, verificam-se números de microrganismos superiores a $10^{5}$, somente nas colheitas do grupo controle e nas anteriores à anti-sepsia nos grupos I e II. No T2 e T3 desses dois grupos, foi encontrado número pouco expressivo de bactérias. $\mathrm{O}$ Streptococcus beta-hemoliticos não fez parte das bactérias isoladas (Figura 1). Segundo RAISER (1995), a simples presença de bactérias em um tecido pouco significa, sendo importante o número delas, não devendo ultrapassar $10^{5}$ a $10^{6}$ microrganismos por mililitro de líquido biológico e somente o Estreptococcus beta-hemolíticos parece capaz de causar infecções em níveis inferiores.

As bactérias isoladas dos swabs coletados na pele dos cães utilizados neste experimento, pertenciam aos gêneros Staphylococcus sp., Micrococcus sp., Bacillus sp., Corynebacterium sp., Proteus sp., Pseudomonas sp., Escherichia coli e Acinetobacter sp. Estes isolados bacterianos foram semelhantes aos encontrados por STUBBS et al., (1996). SWAIM et al. (1991), ao examinar a microflora presente em caninos, encontraram um maior número de bactérias gram-positivas, entre elas Staphylococcus sp., Micrococcus sp. e Bacillus sp., contudo, esporadicamente, foram encontradas bactérias gram-negativas. 
Quanto à estocagem do GC por vários dias, BRASIL (1992) relata a necessidade que esse anti-séptico contenha no mínimo $4 \%$ de álcool, para não ocorrer proliferação de bactérias como Proteus e Pseudomonas. No entanto, após seis meses da preparação do anti-séptico, AYLIFFE et al. (1968) não encontraram qualquer alteração de estabilidade ou sobrevivência bacteriana. Já no presente experimento, após 12 meses da preparação do GC apenas com água destilada a 4\%, encontrava-se absolutamente estável sem qualquer resquício de crescimento bacteriano.

\section{CONCLUSÃo}

Através da observação dos resultados obtidos, pode-se concluir que tanto o método utilizando gluconato de clorexidina $4 \%$ quanto o que utiliza tintura de iodo $2 \%$ são eficientes na redução bacteriana da pele até duas horas após a anti-sepsia.

\section{FONTES DE AQUISIÇÃO}

a- Tryptic Soy Broth - Inlab - Interlab Distribuidora de Produtos Científicos S.A., São Paulo, SP.

b- Lecitina de Soja - Inlab - Interlab Distribuidora de Produtos Científicos S.A., São Paulo, SP

c- Tween 80 - Inlab - Interlab Distribuidora de Produtos Científicos S.A., São Paulo, SP.

d- Tiossulfato de Sódio - Inlab - Interlab Distribuidora de Produtos Científicos S.A., São Paulo, SP.

e- Álcool Etílico 92.85GL - Copersucar, Caixa Postal 65741 São Paulo, SP.

f- Tintura de iodo 2\% - Inlab - Interlab Distribuidora de Produtos Científicos S.A., São Paulo, SP.

g- Gluconato de Clorexidina 4\% - Vico Farma - Farmácia de Manipulação, Sta. Maria, RS.

h- Tryptic Soy Ágar - Difco - Interlab Distribuidora de Produtos Científicos S.A., São Paulo, SP.

i - Ágar Sangue - Difco - Interlab Distribuidora de Produtos Científicos S.A., São Paulo, SP.

\section{REFERÊNCIAS BIBLIOGRÁFICAS}

AYLIFFE, G.A.J., LARROWCLIFF, D.F., LOWBURY, E.J.L. Contaminat of disifectans. Brit Med J, v.22, p.505, 1968.

BLATT, R., MOLONEY, J.V. Evaluation of the iodophor compounds as surgical germicides. Surg Gynecol Obstet, v.113, n.6, p.699-704, 1961.

BRASIL, Ministério da Saúde, Portaria 930, de 27 de agosto de 1992; Anexo V: Normas para limpeza, desinfecção, esterilização e anti-sepsia em estabelecimentos de saúde. Diário Oficial da União, Brasília. 4 set. 1992.

BROWN, T.R., EHRLICH, C.E., STEHMAN, F.B., et al. A clinical evaluation of chlorhexidine gluconate spray as compared with iodophor scrub for preoperative skin preparation. Surg Ginecol \& Obstet, v.158, p.363-366, 1984.

CERQUEIRA, M.C.M. Anti-sepsia princípios gerais e anti- sépticos. In: RODRIGUES, E.A.C. Infecções hospitalares prevenção e controle. São Paulo : Sarvier, 1997. Cap.4. p. $426-434$

DENTON, G.W. Iodophors - disinfection, sterilization and preservation. 4 ed. Philadelphia : Lea \& Febiger,1990. 614p.

ESCOBAR, C.A.B. Avaliação da ação antimicrobiana de substâncias utilizadas na anti-sepsia pré-cirúrgica. Pelotas - RS. 1992. 80p. Dissertação (Mestrado em cirurgia e traumatologia buco-maxilo-facial) - Curso de Pós-graduacão em Odontologia, Universidade Federal de Pelotas, 1992.

FELLER, I., RICHARDS, K.E., PIERSON, C.L. Prevention of postoperative infection. Surg Clin North Am, v.52, p.13611366, 1972.

FOWLER, J.L., SCHUH, J.C.L. Preoperative chemical preparation of the eye a comparison of chlorhexidine diacetate, chlorhexidine gluconate, and povidone-iodine. $\mathbf{J}$ Am Anim Hos Assoc, v.28, p.451-457, 1992.

GARNER, J.S., FAVERO, M.S. Guideline for hand-washing and hospital environmental control. Am J Infec Control, v.14, p.110-126, 1986.

GILMORE, O.J.A., SANDERSON, P.J. Prophylactic interparietal povidone-iodine in abdominal surgery. Brit $\mathbf{J}$ Surg, v. 2, p.792-799, 1975

GOODMAN, L.S., GILMAN, A. As bases farmacológicas da terapêutica. 7 ed. Rio de Janeiro : Guanabara Koogan, 1987. $632 p$.

GROSCHEL, D.H.M., PRUETT, T.L. Surgical antisepsis. Philadelphia : Lea \& Febiger, 1991. 654p.

GRUMADAS, C.E.S., RAISER, A.G., WOUK, A.F.F. et al. Comparacão entre dois métodos de escovação para anti-sepsia das mãos dos componentes da equipe cirúrgica. Ciência Rural, Santa Maria, v.21, n.3, p.379-391, 1991 .

HAUGEN, E., JOHANSEN, J.R. Sensitization of guinea pigs with chlorhexidine. Acta Odont Scand, v.32, n.3, p.173-175, 1974.

LARSON, E. Apic guidelines for use of topical antimicrobial agents. Am J Infect Control v.16, p.253-266, 1988.

KAUL, A.F., JEWETT, J.F. Agents and techniques for disinfection of the skin. Surg Ginecol \& Obstet, v.152, p.677-685, 1981 .

MURRAY, P.R. Manual of clinical microbiology 6 ed. Massachussetts : Library of Congress, 1995. 1482p.

OSUNA, D.J., DeYOUNG, D.J, WALKER, R.L. Comparison of three skin preparation techniques in the dog; part 1 : experimental trial. Vet Surg, v.19, n.1, p.14-19, 1990a.

OSUNA, D.J., DeYOUNG, D.J., WALKER, R.L. Comparison of three skin preparation techniques; part 2: Clinical trial in 100 dogs. Vet Surg, v.19, n.1, p.20-23, 1990b.

PAUL, J.W., GORDON, M.A Efficacy of a chlorhexidine surgical scrub compared to that of a hexacchlorophene and povidone iodine. Vet Med Small Anim Clin v.73, p.573-579, 1978.

PENILDON, S. Anti-sépticos e desinfetantes. 2 ed. Rio de Janeiro : Guanabara Koogan, 1985. 1340p. 
PEREIRA, L.J., LEE, G.M., WADE, K.J. The effect of surgical hand-washing routines on the microbial counts of operating room nurses. Am J Infect Control. v.18, p.354-364, 1990.

PETERSON, A.F., ROSENBERG, A., ALTARY, B.S Comparative evaluation of surgical scrub preparations. Surg Ginec Obstet, v.146, p.63-65, 1978 .

PHILIPS, M.F., VASSEUR, P.B., GREGORY, C.R. Chlorhexidine diacetate versus povidone-iodine for preoperative preparation of the skin: A prospective randomized comparison in dogs and cats. J Am Anim Hosp Assoc, v.27, p.105-108, 1991.

RAISER, A.G. Patologia cirúrgica veterinária. Santa Maria : Centro de Ciências Rurais - UFSM, 1995. V.1. Cap.IV: Infecções cirúrgicas: p.101-112. (Série cadernos didáticos).

RODRIGUES, E.A.C., MENDONÇA, J.S., AMARANTE, J.M.B., et al. Infecções hospitalares prevenção e controle. São Paulo : Sarvier, 1997. 669p.

SANCHEZ, R.I., SWAIM, S.F., NUSBAUM,K.E., et $\boldsymbol{a l}$. Effects of chlorhexidine diacetate and povidone-iodine on wound healing in dogs. Vet Surg, v.17, n.6, p.291-295, 1998.

SEBBEN, J.E. Surgical antisseptics. J Am Academ Derm, v.9, p.759-765, 1983.
SIMMONS, B.P. Guideline for hospital environmental control. Am J Infec Control, v.11, p.97-115, 1983.

SLATTER, D.H. Textbook of small animal surgery. 2 ed. Philadelphia : Saunders, 1993. 2v. 2358p.

SOUZA, N.P., FUGEHARA, J.K., KAWAKA, J. Atividade antibacteriana in vitro da clorexidina em três produtos para uso tópico. F Med, v.84, p.257-258, 1982.

STUBBS, W.P., BELLAH, J.R., VERMAAS-HEKMAN, D., et al. Chlorhexidine gluconate versus chloroxylenol for preoperative skin preparation in dogs. Vet Surg, v.25, p.487494, 1996.

SWAIM, S.F., LEE,A.H. Topical wound medications: A review. J Am Vet Med Assoc, v.190, n.12, p.1588-1593, 1987.

SWAIM, S.F., RIDDEL, K.P., GEIGER, D.L. Evaluation of surgical scrub and antiseptic solutions for surgical preparation of canine paws. J Am Vet Med Assoc, v.198, n.11, p.1941$1945,1991$.

VORHERR, H., VORHERR,V.F., MEHTA, P., et al. Vaginal absorption of povidone-iodine. J Am Med Assoc, v.244, p.2628-2629, 1980.

Ciência Rural, v. 30, n. 3, 2000. 